\title{
Contemporary Malaysian Families: Evidence-Based Interventions
}

\author{
Aminah Abdul Rahman*
}

Malaysian families today are facing numerous challenges related to changing family values and structures, pressures of complex family responsibilities and inadequate support systems. Some of these key challenges include increase in divorce, family dysfunction, child abuse, abandoned babies, domestic violence, drug addiction, HIV/AIDS and family related matters such as family economic instability. At the same time, the impact of globalisation has led to new values being accepted by the young people. Indeed, the challenges that Malaysian families will be facing in the future will be tremendous. Despite changes in their structure, families remain the most basic unit of society. Today's families need support to build resilience to meet life's challenges. The success or failure of each family unit to meet the challenges of the various tasks during the course of development, will determine the future of Malaysian families. Hence, the Ministry of Women, Family and Community Development (MWFCD) and the National Population and Family Development Board (NPFDB) as a lead agency in family matters has spearheaded the national agenda on family which includes policy, research and development as well as intervention programmes.

A family is a living, evolving institution, affected by socio-economic factors as well as by the changes that shape the social environment in which it functions. More often, the changes and transformations have brought both gains and losses to the family institution. Hence, the challenge today is to embody positive changes and secure those in the new environment, and at the same time, to mitigate the negative consequences of changes, without dampening the momentum for positive evolution.

Strong family systems can provide the support for successfully meeting these demands and for encouraging the healthy emotional and physical growth of their individual members. Although families vary in size, structure, organisation, and across cultures, all families are faced with the challenge of making their family the 'no. 1 priority'.

When families break down and fail to provide support for their members, the effects reverberate across society. Therefore, it is important for the entire community to support the formation and strengthening of families. When the government and community work together to create an environment that is conducive to marriage, families and raising children - by shaping values, attitudes and life choices - it is

* Aminah Abdul Rahman is the Director General of Malaysia's National Population and Family Development Board (NPFDB). 
because family matters! Recognising the need to strengthen families towards the realisation of a caring society, quality population and a progressive nation, efforts are being undertaken by the Malaysian Government to ensure that the family institution is strong and resilient.

\section{Trends, Challenges, and Interventions}

Currently, Malaysia has a population of 28.3 million, with a growth rate of $2.5 \%$ per annum. Data from the Population Census 2000 shows that young adults tend to marry at a later age. Consequently, the proportion of never married (single) persons aged 20-34 years continued to increase between 1991 and 2000 from $43.2 \%$ to $48.1 \%$. Among females aged $20-24$ years, $68.5 \%$ were single in 2000 compared to only $60.2 \%$ in 1991 . Similar patterns were also observed for females in the 25-34 age group, as well as among males. The mean age at first marriage has been rising for men and women. Between 1980 and 2000, the mean age at first marriage for men increased from 26.6 years to 28.6 years. For women, the mean age at first marriage increased from 23.5 years to 25.1 years.

The number of households has increased at a higher rate than population growth (3.8\% per annum compared to $2.5 \%$ per annum). Hence, from 4.8 million households in 2000, there are almost 7 million households or families in 2010 . About $66 \%$ are nuclear compared to $60 \%$ during the 1991 Census. There was also a slight increase in other types of families, such as single households and unrelated-persons households.

The average household size has dropped from 4.8 persons in 1991 to 4.6 persons in 2000. Family size has declined due to many reasons. Many women are seeking tertiary education, participating in the labour force and also delaying age at first marriage. Furthermore, more couples are delaying the birth of their child until they are well established professionally and secure economically. The Total Fertility Rate has declined for all age groups, from a high of 6.0 children per woman in 1960 to 2.8 in 2004 and currently around 2.2 children per woman, partly the consequence of increasing age at first marriage. Women are also entering childbearing later and are stopping at a younger age. Malaysia is projected to reach replacement level by the year 2015.

In Malaysia, data on population, households and family are primarily collected by the Department of Statistics, the MWFCD and the NPFDB. To complement population census counts, the NPFDB conducts nationwide sample surveys in between the census years. Some of the population and family surveys were the Malaysian Fertility and Family Survey (1974), Malaysian Population and Family Survey Two (1984), Malaysian Population and Family Survey Three (1994) and Malaysian Population and Family Survey Four (2004). Small scale surveys such as opinion polls, case studies and secondary analysis are also conducted to elicit more in-depth information and data on families. 
Family stress and problems within the family are common issues that confront families. The important question is how to cope with them, i.e., exhibit family resilience in situations of stress, crisis or adversity. Stressful events and issues can bring families closer together or they can divide and shatter them. Based on the available data, the main challenges confronting Malaysian families are:

- finance

- parenting of adolescent children

- changing values

- work-life balance

- gender issues.

The NPFDB's Malaysian Population and Family Survey Four (MPFS 4) conducted in 2004 indicated that finance was the major problem confronted by families. The survey further revealed that, in order to cope with such problems, most of the respondents tended to solve the problems on their own. This financial challenge was also revealed in a study conducted by the NPFDB in July 2008 on the effects of inflation on the family. The study found that many families were willing to change their lifestyles to suit the current economic downturn. Many resorted to cutting back on non-essential household expenses such as vacations and utilising public transportation. As a measure to address rising food and fuel prices, $38 \%$ of mothers were prepared to join the work force to boost the family income. Although some indications of increase in family conflict were evident in the above study, the ability of families to adjust their lifestyles and spending habits bode well for the average Malaysian family.

Contemporary Malaysian families also encounter challenges in parenting their adolescent children (MPFS, 2004). Data from various agencies regarding social problems have also identified this factor. Of late, social problems relating to adolescent sexuality and pregnancy have been highlighted in the media. The newspapers reported that there are 81,000 illegitimate births, and that as many as 257,000 birth certificates issued from 2000 until July 2008 did not record the name of father. ${ }^{1}$ Based on reports filed with police, an average of 100 babies were abandoned each year, but the actual number could be much higher. A recent study relating to 'baby abandonment' indicated that the 'mother' is invariably 'young and unmarried'; the 'father' is not responsible and has 'scooted off'. Rape and other forms of violence against adolescent girls have also been reported. High risk behaviour among adolescents has resulted in STDs, unwanted pregnancy and abortion, as many have little knowledge on contraception, STDs and HIV transmission. The 2004 MPFS findings and media reports have heightened the need to address adolescent sexual and reproductive health (ASRH) more comprehensively. 


\section{Evidence-Based Interventions}

The Government is concerned with emerging issues that threaten our family and social structure as families struggle to cope with the fast tempo of development. To address these issues, there is a need for a comprehensive policy that addresses prevention, intervention and rehabilitation strategies. Towards this end, the MWFCD is responsible for planning, monitoring, implementing and evaluating programmes for core target groups such as families, the elderly, children, women and the disabled in collaboration with civil society and NGOs.

In order to maintain the centrality of the family perspective in social development, a National Family Policy (NFP) has been finalised and is expected to be approved by the Government in the near future. The policy, among others, aims towards the realisation of a caring, strong and resilient family system as enshrined under Vision 2020. A plan of action that accompanies the policy will provide guidelines for all sectors to prioritise issues and actions pertaining to family within various social domains.

The NFP is a policy that urges all stakeholders to consistently have a 'family perspective' in all endeavours. It also emphasises the holistic development of families. The NFP will ensure that all citizens can live in a conducive environment to achieve those values so much needed for family well-being and the development of a resilient nation. It also provides a framework for the implementation of measures designed to better meet the changing needs of Malaysian families through the six domains that have been identified to ensure the well-being of families and improve their quality of life. The six domains are:

- strengthening of core family values

- making the family a corporate value

- strengthening of the institution of marriage

- meeting of parenting needs of families

- building of strong foundations for teenagers

- family support services.

The MWFCD and NPFDB had spearheaded the country's policies and programmes related to sexual and reproductive health. A National Reproductive Health and Social Education Policy was initiated by the Ministry and adopted in 2010. The strategies under this policy and its plan of action include advocacy and multi-sectoral cooperation, and constant evaluation and monitoring. The policy is aimed at producing individuals that are knowledgeable and imbued with positive attitudes. The objectives of this policy are: 
- to increase the awareness of members of the society on reproductive health and social education;

- to develop expertise in reproductive health and social education;

- to enhance research and development; and

- to improve the effectiveness of the implementation of reproductive health and social policy.

To address the issue on adolescent sexual and reproductive health (ASRH) and HIV/AIDS, the MWFCD and NPFDB are focusing on educating the young through a special project named "Improved existing RH package under kafe@ TEEN programme for Up-scaling with Involvement from Key Stakeholders". Five adolescent and youth centres known as kafe@TEEN have been established to provide information, knowledge and skills on adolescent sexuality and reproductive health, as well as ASRH and counselling services for the adolescents. Under the Up-scaling kafe@TEEN programme, the 'I'm In Control Module' for adolescents and young people was developed in 2008 and pilot tested in 2009 at five schools and kafe@TEEN centres in five states in Peninsular Malaysia - Wilayah Persekutuan Kuala Lumpur, Selangor, Pahang, Kelantan and Penang. In 2010, workshops based on this module were conducted at the same five schools and kafe@TEEN centres. It has also been implemented by various NGOs as well as under the 'LPPKN@ Komuniti' programme for adolescents from low income household families. A module for parents has also been developed under this project to provide the right information on ASRH and skills on dealing with ASRH issues.

Although findings from the MPFS 4 (2004) survey revealed that almost $99 \%$ of husbands and wives perceived their family relationships to be strong and cohesive, the need to address the increasing incidence of divorce resulted in the Government taking affirmative action to further strengthen the marriage institution and promote strong resilient families. The SMARTSTART pre-marriage course conducted for couples intending to get married and those married for less than five years aims to provide them with the relevant information, knowledge and skills to equip them to face challenges in married life. Grants are given to NGOs to conduct this course in four main languages - Malay, English, Tamil and Mandarin - to cater to the diverse ethnic backgrounds of Malaysians.

Recognising the increasing participation of women in the labour force and the subsequent increase in dual career families, actions have been taken to create awareness and provide knowledge to parents on the importance and need to balance work and family. Therefore, the Parenting@Work programme was launched in 2007 to provide guidance on parenting skills, ensure stable and resilient family units and to equip families to face modern-day challenges and work-life balance issues. To date, 350 programmes have been conducted at Government Ministries and agencies 
from the Federal and State level. The programme has also been expanded to the private sector. Since 2007, almost 15,000 participants from the government and private sector have attended this programme. A strategic collaboration with local non-government organisations (NGOs) was initiated early in 2010 to ensure the programme is implemented at the community and grass root level. Based on the feedback from 10,000 participants (2008-10), more than 90\% said after attending this programme that they acquired new knowledge, ideas and skills on dealing with issues and challenges of work-life integration.

Acknowledging the need for a family financial programme, NPFDB introduced a financial management programme called 'SMARTBelanja@LPPKN' in 2009 to educate family members, especially the young families, to prepare them for good family financial management. One of the main focus points of this programme is to guide and teach participants to differentiate between 'needs' and 'wants'. The knowledge and skills gained from the interactive workshop will enable them to better manage their financial resources.

In tandem with the Government Transformation Programme and National Key Result Area or NKRA for Low Income households, NPFDB has initiated an outreach programme called 'LPPKN@Komuniti'. This NKRA programme was launched by the Government in April 2009 and the MWFCD was given the responsibility to lead the NKRA on eradicating hard core poverty by the end of December 2010 and reducing the poverty rate from $3.6 \%$ in 2007 to $2.8 \%$ in 2010 . The low income households identified under the NKRA, have been equipped with knowledge and skills on parenting, financial management and reproductive health education as well as counselling services, under this 'LPPKN@Komuniti' programme which aims at raising the quality of life and improving the status of families, particularly rural families.

The goal of family resilience is to ensure that families are able to cope with any kind of challenge. In Malaysia, various initiatives, programmes and services to support families are already in place as a preventive measure to assist those experiencing difficulty in coping with current challenges.

As a way forward, the Government will continue its effort to enhance the safety and resiliency of families. To this end, integrated family centres are being established at the state level and another 55 centres will be in operation at the district level under the Ministry and NPFDB. These integrated family centres serve as "one stop centres" that conduct educational and training programmes on family development as well as providing services such as counselling and reproductive health clinical services. The aim of the centres is to facilitate and accelerate the realisation of individuals and families which are resilient, ethical, healthy, knowledgeable and harmonious through effective, friendly and quality delivery services. To ensure the services 
provided are accessible to the community at the grass root level, currently six mobile family centres are available but it will be increased to 15 in the near future.

In order to describe, monitor and track the well-being of the family as a whole in coping with current changes and their impact on the Malaysian society and families, the NPFDB is currently embarking on a project to build a set of indicators on family well-being to serve as baseline information. As there is no one indicator that can capture the full dimension of the domain on family, a group of Malaysian experts are in the midst of discussing and reaching agreement on the concept of family and family well-being as well as identifying the indicators that can be used to measure family well-being. The indicators identified will be tested and a field study to measure family well-being will be carried out in 2011. In addition, the 2010 Population Census will be able to provide the latest demographic trends and assist policy planners in developing family-centred programmes and services.

In addition to this, research on the current and emerging population and family related issues including the needs of special groups such as the elderly, single parents and adolescents needs to be undertaken. Results of these research activities will contribute towards the formulation of relevant social policies and intervention programmes especially in strengthening the family unit. A strengths-based approach centred on the premise that every family has inherent strengths and resources will be able to empower families to cope with challenges without their being dependent solely on external assistance.

\section{Conclusions and Recommendations}

A strong family unity inculcated with positive family values, shared responsibilities among family members and a strong marriage institution will continue to be a priority of the Government's development agenda.

- Families are the cornerstone of a healthy, dynamic and productive nation and are essential in fulfilling the emotional and physical needs of individuals, which are necessary for the achievement of good economic and social outcomes.

- Therefore, the 10th Malaysia Plan (2011-15) places emphasis on programmes that instil character-building and family values to promote greater resilience, integrity, solidarity and well-being of the family institution.

- Family friendly policies, services and programmes should continue to be the main focus on strengthening marriage and the family institution.

\section{Note}

1. Archives, 30 June 2010, and Utusan Malaysia [Kuala Lumpur], 2 July 2010. 